\title{
Active learning reduces academic risk of students with nonformal reasoning skills: Evidence from an introductory physics massive course in a Chilean public university
}

\author{
Guillaume Lagubeau $\odot,{ }^{*}$ Silvia Tecpan $\odot,^{\dagger}$ and Carla Hernández $\odot^{*}$ \\ Departamento de Física, Universidad de Santiago de Chile, Santiago de Chile, \\ Region Metropolitana, 9170124, Chile
}

(Received 24 August 2019; accepted 1 July 2020; published 14 July 2020)

\begin{abstract}
We present the findings of a pilot plan of active learning implemented in introductory physics in a Chilean public university. The model is research based as it considered a literature review for adequate selection and design of activities consistent with the levels of students' reasoning skills. The level of scientific reasoning is positively correlated to student success. By contrast to a control group of students following traditional lectures, we observed a significant reduction in failure rate for students that do not yet possess formal scientific reasoning. This profile of students being the majority, we conclude that implementing active learning is particularly suited to the first year of higher education in the context of a developing country. It fits the particularities of student profile and typical classroom size, leading to learning improvement and reduction of academic risk, as well as being financially sound.
\end{abstract}

DOI: 10.1103/PhysRevPhysEducRes.16.023101

\section{INTRODUCTION}

Low student enrollment and high attrition rates in science, technology, engineering, and mathematics (STEM) education are part of the major contemporary challenges in higher education [1]. As a consequence, introductory physics courses usually become filter courses for numerous engineering students [2], which is reflected in the historical failure rate for the first engineering physics course in our institution. In an effort to reduce academic risk, as well as to better prepare engineering students for the 21 st century, a methodological change in the teaching method $[3,4]$ was decided upon in our institution. Strong evidence accumulated over the past 35 years of significant gains in active learning of physics [5-7] motivated a pilot program of implementation of research-based [8] active learning in introductory physics course.

The pilot program's main challenges were making it realistically scalable for encompassing a large enrollment course (1600 students) and adapting innovative strategies to the context of our traditional and public university. Our institution has an inclusive access policy that favors admissions to higher education of students with very heterogeneous profiles. Some students are admitted for

\footnotetext{
*guillaume.lagubeau@usach.cl

silvia.tecpan@usach.cl

carla.hernandez.s@usach.cl
}

Published by the American Physical Society under the terms of the Creative Commons Attribution 4.0 International license. Further distribution of this work must maintain attribution to the author(s) and the published article's title, journal citation, and DOI. their performance in the university selection test, while others for their results in high school, even if their selection test results were insufficient $[9,10]$. This politics is oriented to reduce the socio-economic gap in STEM education. Indeed, the Chilean context is different from the countries were most of the active learning material is developed (with the exception of Mexico), as it presents the particularity of a below-average Programme for International Student Assessment (PISA) result. Historically, students in Chile have obtained lower scores than the average of OECD countries in reading, math, and science. Around 65\% of students in Chile reached Level 2 (of 6) or higher in science and $48 \%$ in mathematics (OECD average: $78 \%$ and $76 \%$, respectively) [11]. Level 2 implies that "students can interpret and recognise situations in contexts that require no more than direct inference" [11]. Moreover, as stated in the PISA report, "Socio-economic status was a strong predictor of performance in mathematics and science in all PISA participating countries." It explained $16 \%$ of the variation in mathematics performance in PISA 2018 in Chile (compared to $14 \%$ on average across OECD countries), and $14 \%$ of the variation in science performance (compared to the OECD average of $13 \%$ of the variation). Therefore, and considering that deep understanding of physics concepts requires a high level of scientific reasoning $[12,13]$, it is essential to characterize the level of scientific reasoning of our introductory physics course students before tailoring a teaching sequence consistent with their profiles $[14,15]$.

In this paper we present results of the implementation and adaptation of active methodologies at the pilot level, to transform introductory physics in an engineering program 
that considers the profile and diversity of students. This model is inspired by previous similar experiences both in Latin America [16-19] and others countries [20-22].

\section{THEORETICAL FRAMEWORK}

\section{A. Active learning strategies}

Students' level of scientific reasoning is well reported to be a determining factor in academic success in the first years of university science courses [13-15]. Methodologies that promote active learning, that is designing lectures where the student is intellectually active [23], have been found to improve scientific reasoning [24,25], and are helpful for students with low socioeconomic background [26].

Various effective active learning strategies focused on the need to enhance conceptual learning, problem solving skills, collaborative work, and hypothesis generation among other skills required for the training of engineers in the 21 st century have been developed during the last decades. In particular, we used tutorials [27], interactive lecture demonstration [28], peer instruction [29], sensemaking tasks [30], and collaborative solving problems [31] fitting the program of the course (introductory mechanics and statics). In the Supplemental Material [32], we provide a list of the activities used for the active learning sessions.

\section{B. Scale-Up rooms}

For supporting the actives lecture, Scale-Up rooms [33] were build for this project, of capacity 54 students. Their design promotes student-centered learning as the teacher is not the focal point. Five projectors provide good visibility of projected material for all students. The furniture consisted initially of normal tables and chairs, arranged in groups of 9 people to work in microgroups of 3 students, and latter large round desks that facilitate collaborative work were installed, as seen in Fig. 1 bottom. The entire wall of the room is covered with boards. In addition, blackboards of $60 \mathrm{~cm} \times$ $80 \mathrm{~cm}$ are freely available in room for every group of students. Finally, the room layout allowed an easy circulation of students and professors between desks.

Such a methodological change may be associated with an increment in infrastructure and personal costs per student [34]. It is due to reducing section sizes and thus increasing the number of sections in massive courses. Because of the layout and infrastructure of the university, it is not the case in our university: the average section of introductory physics is composed of 50 students ( $31 \mathrm{sec}-$ tions for approximately 1550 students in total). Scaling up the pilot plan would be realized at a constant number of sections and professors.

\section{METHODS}

\section{A. Work flow}

The teaching material was designed by a coordination team, distinct from the group of teachers. Interactive
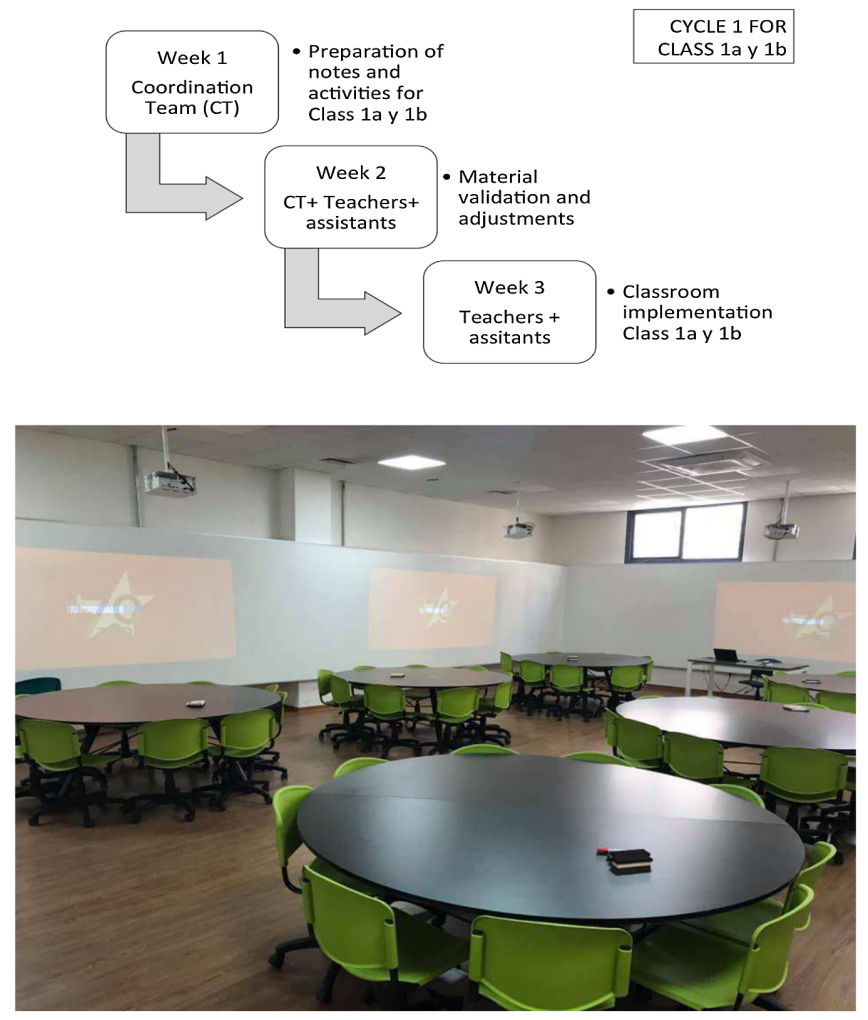

FIG. 1. Top: Work cycle. Bottom: Student centered classroom.

lectures were given by a professor accompanied by a teaching assistant. The professors had already taught the same course in a traditional way previously, and undergraduate students of our university served as teaching assistants. Both professors and teaching assistants were present simultaneously during lecture to support the student's learning process. Implementing active learning strategies in the classroom requires preparation work that we structured in a three-stage cycle (Fig. 1 top).

The first stage consists of the coordination team reviewing the literature to prepare the activities that would be used in the two classes occurring two weeks after. In the second stage, the proposed activities are tested in a meeting between the coordination team, the professors, and the teaching assistants, and then reviewed and adjusted if necessary. Finally, in stage three, teachers and assistants implement activities in the classroom. This process started two weeks before starting the semester and was repeated each week. For sharing course content with professors and teacher assistants, the coordinating team also created an online repository of material and the essential bibliographical references.

Following the flipped classroom model $[35,36]$ material is provided to the students gradually: Elements of theory and exercises to complement traditional classes, identical with those of the previous semester, were provided before the active session through a virtual institutional platform. Indeed this material is available to all the students, in active modality or not. 


\section{B. Experimental design}

From a total of 31 section taking lectures in the first semester of 2019, 4 were experimental (active learning) and 4 sections used as the control group. Both the experimental and control groups' exams were identical. The control group election was based on equivalent historical results, stable during the 3 years before this project. Both groups reasoning skills were characterized by taking the Lawson classroom test of scientific reasoning [37] at the start of the semester.

Both control and experimental groups followed the same weekly program of contents and had access to the same bibliography or online material. Indeed, online material and evaluations were not innovated and were similar to previous semesters. The experimental group followed during a 17-week semester two active lectures of $1 \mathrm{~h} 30 \mathrm{~min}$ each and an exercise session of $1 \mathrm{~h} 30 \mathrm{~min}$, the later unmodified between the control and experimental groups. The control group had the same schedule but using traditional teaching. Three evaluations (identical for all students) were carried out with three problems each, prepared by a teaching committee not included in the implementation of the pilot plan.

\section{Failure rate analysis}

For consistency with the meta-analysis of Freeman [5], we compare the failure rate of students defined as the number of students failing the course divided by the total number of students. We only consider students that attended all the evaluations during the semester forming a universe of 304 students, 146 of which followed traditional learning and 158 active learning. For determining the statistical significance of the difference in failure rate, we test the following hypothesis $\left(H_{0}\right)$ : "introductory physics students following active lecture are less likely to fail than students following traditional lecture." The null hypothesis is then that "introductory physics students following active lecture are as likely or more likely to fail than students following traditional lecture." Our statistical analysis is the following: failing or passing a course is a binary process. Thus, evaluating the failure rate is equivalent to estimating a so-called "cut efficiency." Bayes analysis allows us to theoretically calculate the uncertainty of efficiency measurement due to size effect [38]. If $k$ is the number of positive cases and $n$ the population, the probability distribution of the efficiency is a beta distribution of parameters $(\alpha=k+1$, $\beta=n-k+1)$. We can then calculate the density probability of the variation in failure rate (as shown in Fig. 3) and therefore estimate $p\left(H_{0}\right)$.

\section{Scientific reasoning diagnostic}

During the two first weeks of the semester, students of the control and experimental groups took the Lawson
TABLE I. Failure rate in introductory physics as a function of gender. $p\left(H_{O}\right)$ is the probability that failure rates decrease by introducing active learning.

\begin{tabular}{lrcccc}
\hline \hline & \multicolumn{1}{c}{$N$} & Traditional & Active & Variation & $p\left(H_{0}\right)$ \\
\hline Female & 76 & $67.9 \%$ & $47.9 \%$ & $-20.0 \%$ & $94.7 \%$ \\
Male & 228 & $39.8 \%$ & $30.9 \%$ & $-8.9 \%$ & $90.7 \%$ \\
\hline \hline
\end{tabular}

classroom test of scientific reasoning [37]. The test is composed of 24 questions, organized by pairs. Bao [39] and Mashood [40] used the distribution of correct answer as an indicator of typical reasoning skills in first year of university, comparing different cultures. For our study, a total of 260 students took the reasoning test and were present in all evaluations of the semester (149 from active groups and 111 from the control group).

\section{RESULTS}

By comparing the results of an experimental group following active learning and a control group, we found a $9.1 \%\left[p\left(H_{0}\right)=0.937\right]$ reduction in failure rate, statistically significant and coherent with previous reports [5]. In addition, students with a transitional reasoning level, being the majority in our context, benefited most from the innovation.

\section{A. Failure rate reduction}

Failure rate was $45.2 \%$ for students following traditional learning, comparable to the historic rate $(45.7 \%$, considering only students that attended all evaluations). By contrast, active learning students failing rate was $36.1 \%$, evidencing a $9.1 \%$ improvement $\left[p\left(H_{0}\right)=0.937\right]$ consistent with improvement reported in literature for physics and STEM [5]. We conclude that active learning methodology is particularly well suited in the Chilean context for teaching introductory physics contents.

Separating results by gender, one can note that while in both modalities, the female failure rate was higher than the male failure rate, female students benefited more from the innovation than male students (see Table I): female students following traditional learning were 1.41 time more likely to fail than those following active learning (1.29 for male students).

\section{B. Correlation between reasoning skills and active learning efficiency}

For comparison with previous cross cultural studies $[39,40]$, in Fig. 2 top, we present the distribution of students as a function of the number of correct answer to the Lawson classroom test of scientific reasoning.

The average reasoning level in our student universe was found significantly lower $(60.3 \%)$ than those reported in 


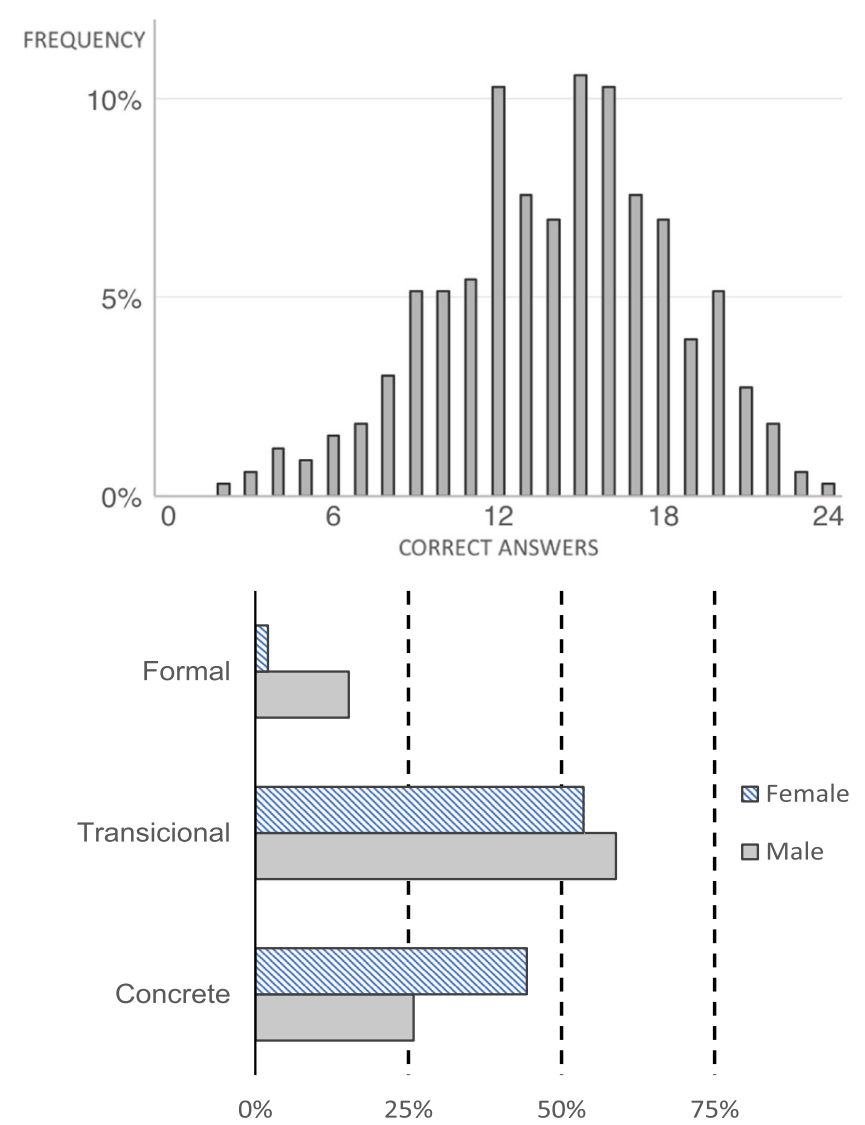

FIG. 2. Top: Distribution of students as a function of the number of correct answers. Bottom: Categorization of scientific reasoning level for introductory physics students, experimental, and control groups combined (Male: $N=228$, Female: $N=76$ ).

USA (74.2\%), China (74.7\%), and India (69.3\%) thus evidencing our local need to adapt to a profile of student with scientific reasoning skills not yet fully developed. A pair analysis of answers allows us to sort the students into three reasoning levels [37]: the so called "concrete," "transitional," and "formal" reasoning skills. At the concrete level (0-4 pairs) students are able to classify objects and understand conservation, but not yet able to form hypotheses. At the formal level (9-12 pairs), students can think abstractly and are able to control and isolate variables, among other similar tasks. At the transitional level (5-8 pairs), students are only capable of partial formal reasoning [15].

TABLE II. Failure rate in introductory physics: Global result and detail by preinstruction reasoning skills. $p\left(H_{O}\right)$ is the probability that the failure rate decreased by introducing active learning. Bold type is used when $H_{O}$ is statistically likely.

\begin{tabular}{lccccc}
\hline \hline & $N$ & Traditional & Active & Variation & $p\left(H_{0}\right)$ \\
\hline Concrete & 73 & $52.6 \%$ & $54.3 \%$ & $1.7 \%$ & $42.7 \%$ \\
Transitional & $\mathbf{1 5 2}$ & $\mathbf{4 5 . 0 \%}$ & $\mathbf{3 1 . 5 \%}$ & $\mathbf{- 1 3 . 5 \%}$ & $\mathbf{9 4 . 7 \%}$ \\
Formal & 35 & $18.8 \%$ & $21.1 \%$ & $2.2 \%$ & $43.2 \%$ \\
\hline \hline
\end{tabular}

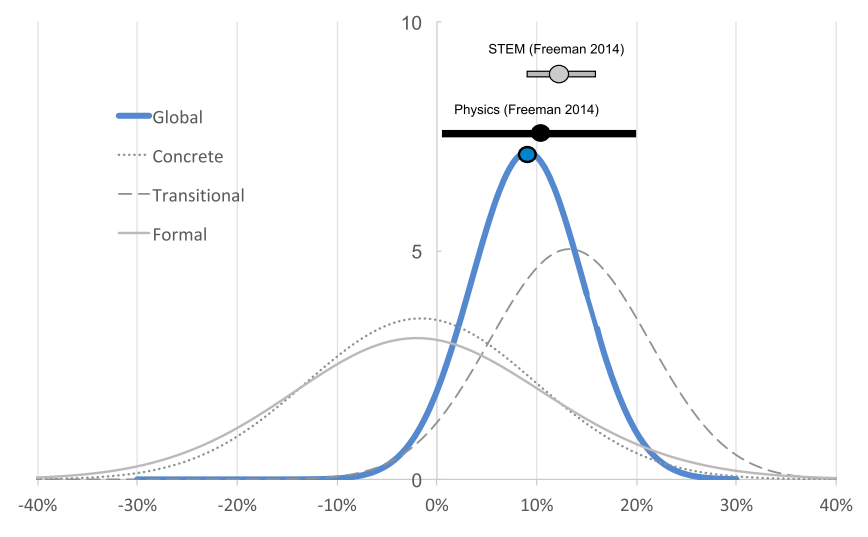

FIG. 3. Difference in failure rate between experimental and control groups. Probability distributions for the whole student universe as well as distinction of concrete, transitional, and formal reasoning skills are shown.

In Fig. 2 bottom we present the categorization of our introductory physics students, separated by gender. The majority of students are observed to be still in a transitional level of reasoning. In light of this diagnostic, coherent with the low inference skills detected in PISA results [11], obtained early in the semester (week 3), we orientated classroom activities to likely favor students with transitional or concrete reasoning skills. The adaptation consisted of shortening the duration of each activity and giving priority to guided student work. In particular we used tutorials focused on step-by-step reasoning [27]. Indeed, this raises the need to specifically adapt the first year of our engineering curriculum to progressively improve reasoning skills. The gender gap in the results is to be noted, and consistent with the gender gap observed in STEM college admission results in Chile [41].

In Table II we present failure rates separated by reasoning skills for both the experimental and control groups. The reasoning skills level is correlated to the probability of passing the course: concrete students were approximately 1.7 times less likely to pass the course than transitional students and 2.5 times less likely than formal students. While we observed a null effect on concrete and formal students, active methodology strongly reduced the failure rate of transitional students $(-13.5 \%)$ as can be seen in Table II and Fig. 3. Results are statistically significant.

\section{CONCLUSION}

We implemented evidence-based active learning lectures in an introductory physics course for engineering in a country with below average PISA results in mathematics and science. Our study evidences specifically a lower academic risk for students that had not yet developed formal reasoning skills, that being the vast majority of students entering our university. 
In light of the pilot plan, all sections of introductory physics for engineering will use this methodology starting in 2020. Extrapolation of our findings indicates a potential increment of 150 students passing the course each year. Our university infrastructure, quite common in developing countries, already is formed of medium sized classrooms (50 students). As a consequence, implementing active learning does not increase the number of sections, making it financially sound: the initial investment of one classroom renovation, being equivalent to 8 student fees, would be compensated for in less than one year by the reduction of academic risk.

\section{ACKNOWLEDGMENTS}

We thank Vicerrectoría Académica USACH through Convenio Marco CM USA1856, and the Engineering Faculty of USACH. C. H. is supported by CONICYT through Proyecto Fondecyt de Iniciación No. 11170580. S. T. thanks the Proyecto DICYT USACH No. 031931TF. The authors would also like to thank Professor Rodrigo Canto, Professor Juan Francisco Fuentealba, Professor Marcia Melendez, and the teaching assistants Angel Barra, Ali Godoy, Matias Herrera, and Cristobal Hormazabal for their dedication to the project.
[1] A. Sithole, E. T. Chiyaka, P. McCarthy, D. M. Mupinga, B. K. Bucklein, and J. Kibirige, Student attraction, persistence and retention in stem programs: Successes and continuing challenges, Higher Educ. Studies 7, 46 (2017).

[2] H. Vasquez, A. A. Fuentes, J. A. Kypuros, and M. Azarbayejani, Early identification of at-risk students in a lower-level engineering gatekeeper course, in 2015 IEEE Frontiers in Education Conference (FIE), El Paso, TX, USA (IEEE, 2015), pp. 1-9, https://doi.org/10.1109/ FIE.2015.7344361.

[3] Universidad de Santiago de Chile, Modelo Educativo Institucional (2013), https://www.usach.cl/sites/default/ files/documentos/files/mei_2014.pdf.

[4] https://www.consortium2030.cl/.

[5] S. Freeman, S. L. Eddy, M. McDonough, M. K. Smith, N. Okoroafor, H. Jordt, and M. P. Wenderoth, Active learning increases student performance in science, engineering, and mathematics, Proc. Natl. Acad. Sci. U.S.A. 111, 8410 (2014).

[6] C. H. Crouch and E. Mazur, Peer instruction: Ten years of experience and results, Am. J. Phys. 69, 970 (2001).

[7] M. D. Sharma, I. D. Johnston, H. Johnston, K. Varvell, G. Robertson, A. Hopkins, C. Stewart, I. Cooper, and R. Thornton, Use of interactive lecture demonstrations: A ten year study, Phys. Rev. ST Phys. Educ. Res. 6, 020119 (2010).

[8] G. M. Bubou, I. T. Offor, and A. S. Bappa, Why researchinformed teaching in engineering education? A review of the evidence, Eur. J. Eng. Educ. 42, 323 (2017).

[9] M. V. Santelices, X. Catalán, C. Horn, and A. Venegas, High school ranking in university admissions at a national level: Theory of action and early results from Chile, Higher Educ. Policy 31, 159 (2018).

[10] M. V. Santelices, C. Horn, and X. Catalán, Institution-level admissions initiatives in Chile: Enhancing equity in higher education?, Studies Higher Educ. 44, 733 (2019).

[11] OECD, PISA 2018 Results (Volume I) What Students Know and Can Do (PISA, OECD Publishing, Paris, 2019), https://doi.org/10.1787/5f07c754-en.

[12] A. E. Lawson, Teaching Inquiry Science in Middle and Secondary Schools (Sage, Thousand Oaks, CA, 2010).
[13] C. Fabby, Examining the relationship of scientific reasoning with physics problem solving, J. STEM Educ. 16, 20 (2015), https://www.jstem.org/jstem/index.php/JSTEM/ article/view/1904.

[14] V. P. Coletta, J. A. Phillips, and J. J. Steinert, Why you should measure your students' reasoning ability, Phys. Teach. 45, 235 (2007).

[15] V. P. Coletta and J. A. Phillips, Interpreting FCI scores: Normalized gain, preinstruction scores, and scientific reasoning ability, Am. J. Phys. 73, 1172 (2005).

[16] G. Zavala, H. Alarcón, and J. Benegas, Innovative training of in-service teachers for active learning: A short teacher development course based on physics education research, J. Sci. Teach. Educ. 18, 559 (2007).

[17] G. Zavala and H. Alarcon, Evaluation of instruction using the conceptual survey of electricity and magnetism in Mexico, AIP Conf. Proc. 1064, 231 (2008).

[18] A. Auyuanet, H. Modzelewski, S. Loureiro, D. Alessandrini, and M. Míguez, Físicactiva: Applying active learning strategies to a large engineering lecture, Eur. J. Eng. Educ. 43, 55 (2018).

[19] C. Hernández and S. Tecpan, Correct answers with wrong justifications? Analysis of explanations in classical mechanics with FCI test, J. Phys. Conf. Ser. 1043, 012056 (2018).

[20] E. F. Redish, Oersted lecture 2013: How should we think about how our students think?, Am. J. Phys. 82, 537 (2014).

[21] A. L. Rudolph, B. Lamine, M. Joyce, H. Vignolles, and D. Consiglio, Introduction of interactive learning into French university physics classrooms, Phys. Rev. ST Phys. Educ. Res. 10, 010103 (2014).

[22] L. Deslauriers, E. Schelew, and C. Wieman, Improved learning in a large-enrollment physics class, Science 332, 862 (2011).

[23] D. E. Meltzer and R. K. Thornton, Resource letter alip-1: Active-learning instruction in physics, Am. J. Phys. 80, 478 (2012).

[24] L. Ding, Detecting progression of scientific reasoning among university science and engineering students, in Proceedings of the 2013 Physics Education Conference, 
Portland, OR, edited by P. V. Engelhardt, A. D. Churukian, and D. L. Jones (AIP, New York, 2013), pp. 125-128.

[25] C. Fabby and K. Koenig, Relationship of scientific reasoning to solving different physics problem types, in Proceedings of the 2013 Physics Education Conference, Portland, OR, edited by P. V. Engelhardt, A. D. Churukian, and D. L. Jones (AIP, New York, 2013), p. 141.

[26] P. Sinnayah, J. A. Rathner, D. Loton, R. Klein, and P. Hartley, A combination of active learning strategies improves student academic outcomes in first-year paramedic bioscience, Adv. Physiol. Educ. 43, 233 (2019).

[27] L. C. McDermott and P. S. Shaffer, Tutoriales para Física Introductoria (Pearson Education, London, 1997).

[28] D. R. Sokoloff and R. K. Thornton, Interactive lecture demonstrations, in Interactive Lecture Demonstrations, edited by D. R. Sokoloff and R. K. Thornton (John Wiley \& Sons, Hoboken, NJ, 2004), p. 374.

[29] E. Mazur, Peer Instruction: A User's Manual (AddisonWesley, Reading, MA, 1999).

[30] C. J. Hieggelke, S. E. Kanim, T. L. O'Kuma, and D. P. Maloney, TIPERs: Sensemaking Tasks for Introductory Physics (Pearson, London, 2015).

[31] P. Heller, R. Keith, and S. Anderson, Teaching problem solving through cooperative grouping. part 1: Group versus individual problem solving, Am. J. Phys. 60, 627 (1992).

[32] See Supplemental Material at http://link.aps.org/ supplemental/10.1103/PhysRevPhysEducRes.16.023101 for list of the activities used for the active learning sessions.

[33] R. J. Beichner, J. M. Saul, D. S. Abbott, J. J. Morse, D. Deardorff, R. J. Allain, S. W. Bonham, M. H. Dancy, and J. S. Risley, The student-centered activities for large enrollment undergraduate programs (scale-up) project, Research- based Reform Univ. Phys. 1, 2 (2007), http://per-central .org/per_reviews/media/volume1/SCALE-UP-2007.pdf.

[34] E. Brewe, R. Dou, and R. Shand, Costs of success: Financial implications of implementation of active learning in introductory physics courses for students and administrators, Phys. Rev. Phys. Educ. Res. 14, 010109 (2018).

[35] W. H. Fox-Turnbull, P. Docherty, and P. Zaka, Learning engineering through the flipped classroom approachstudents' perspectives, Design Technology Educ.: An Int. J. 23, 26 (2018), https://ojs.lboro.ac.uk/DATE/article/ view/2470.

[36] C. Hernández-Silva and S. Tecpan Flores, Aula invertida mediada por el uso de plataformas virtuales: Un estudio de caso en la formación de profesores de física, Estudios pedagógicos (Valdivia) 43, 193 (2017).

[37] L. Bao, Y. Xiao, K. Koenig, and J. Han, Validity evaluation of the Lawson classroom test of scientific reasoning, Phys. Rev. Phys. Educ. Res. 14, 020106 (2018).

[38] M. Paterno, Calculating efficiencies and their uncertainties, Technical Report No. FERMILAB-TM-2286-CD, Fermi National Accelerator Lab.(FNAL), Batavia, IL (United States), 2004.

[39] L. Bao, T. Cai, K. Koenig, K. Fang, J. Han, J. Wang, Q. Liu, L. Ding, L. Cui, Y. Luo et al., Learning and scientific reasoning, Science 323, 586 (2009).

[40] K. Mashood and V. A. Singh, Preuniversity science education in India: Insights and cross cultural comparison, Phys. Rev. Phys. Educ. Res. 15, 013103 (2019).

[41] F. Gándara and M. Silva, Understanding the gender gap in science and engineering: Evidence from the Chilean college admissions tests, Int. J. Sci. Math. Educ. 14, 1079 (2016). 